\title{
Cardiac manifestations in Emery-Dreifuss muscular dystrophy
}

\author{
Whitney Faiella MD, Ricardo Bessoudo MD
}

— Cite as: CMAJ 2018 December 3;190:E1414-7. doi: 10.1503/cmaj.180410

A 35-year-old man with a known history of Emery-Dreifuss muscular dystrophy called emergency medical services (EMS) while at work one morning, reporting palpitations, lightheadedness, fatigue and a rapid heart rate. On arrival by EMS, his pulse was documented at 195-200 beats/min, and his rhythm strips showed ventricular tachycardia (Figure 1A). He underwent cardioversion and was given a bolus of amiodarone, $150 \mathrm{mg}$ intravenously. In the emergency department and during admission, his symptoms persisted with rhythm strips showing recurrent episodes of sustained ventricular tachycardia (Figure 1B). He was subsequently started on an amiodarone drip and oral metoprolol. Echocardiography performed during admission showed dilated cardiomyopathy with severe systolic dysfunction and an estimated ejection fraction of $23 \%$. Cardiac catheterization was performed to rule out an ischemic cause of the cardiomyopathy and showed normal coronary arteries. The patient received an implantable cardioverter-defibrillator and was discharged with prescriptions for an oral $\beta$-blocker and amiodarone. As an outpatient, his amiodarone is slowly being weaned because he has had no recurrent episodes of ventricular tachycardia.

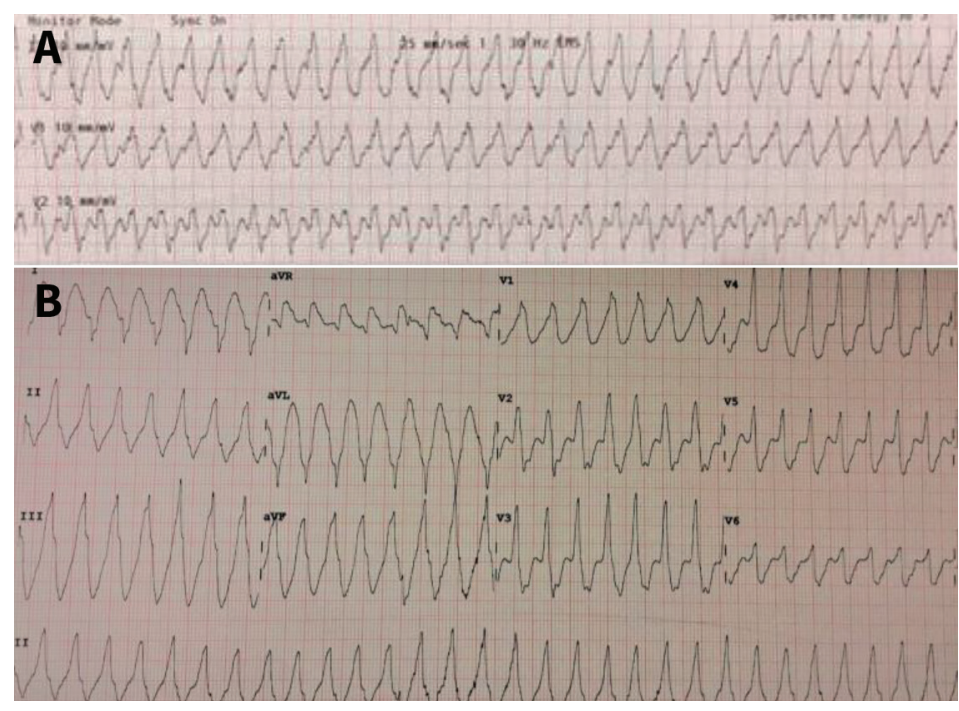

Figure 1: Rhythm strips in a 35-year-old man with Emery-Dreifuss muscular dystrophy, documenting wide complex tachycardia consistent with ventricular tachycardia. A) Initial 3-lead rhythm strip performed on site by emergency medical services, with a documented heart rate of 195 beats/min. B) Initial 12-lead electrocardiogram performed in the emergency department, with a documented heart rate of 186 beats/min.

\section{KEY POINTS}

- Emery-Dreifuss muscular dystrophy is one of many neuromuscular diseases with cardiac involvement, including bradyarrhythmia, tachyarrhythmia and cardiomyopathy, and involves an increased risk of sudden cardiac death.

- A recently published scientific statement highlights key cardiac manifestations in various forms of neuromuscular diseases and includes detailed recommendations regarding screening, follow-up and treatment for each individual disease.

- Medical optimization of cardiac function and early detection of arrhythmias with subsequent insertion of a pacemaker or defibrillator can be life-saving in this patient population.

With respect to the patient's diagnosis of Emery-Dreifuss muscular dystrophy, he first saw a neurologist at age 14 years after multiple operations to lengthen his Achilles tendon owing to persistent "toe walking," which is characteristic of the disease. He was subsequently referred to a muscular dystrophy specialist at age 15, when the diagnosis of Emery-Dreifuss muscular dystrophy was confirmed. Aside from the contractures of his Achilles tendons, he also has substantial difficulty with neck flexion secondary to contractures in his neck extensors. The patient lives in a community with limited access to specialist care and has therefore not followed up with a muscular dystrophy specialist since age 15 , because it would require substantial travel to a larger tertiary care centre.

The patient's first echocardiogram at age 15 showed a dilated cardiomyopathy with an ejection fraction of $45 \%$ $50 \%$. He was subsequently started on an angiotensinconverting enzyme (ACE) inhibitor by a cardiologist. He elected not to start a $\beta$-blocker because of potential adverse effects, including fatigue. Subsequently, he had a total of 4 follow-up appointments over the next 20 years with his cardiologist, where he remained completely asymptomatic from a cardiac perspective. He underwent serial echocardiography tests, which ultimately showed progression of his cardiomyopathy. His next echocardiogram almost 10 years later showed a dilated left ventricle with mild global systolic dysfunction (ejection fraction of $45 \%$ ), which progressed to moderate left ventricular systolic dysfunction (ejection fraction of $35 \%-40 \%$ ) over the 
next 4 years and to severe left ventricular systolic dysfunction (ejection fraction of $23 \%$ ) on this current admission.

A few months before this current admission, electrocardiography (ECG) showed a new first-degree atrioventricular block. During this hospital admission, telemetry captured rhythms including sinus bradycardia and a second-degree (Mobitz type I) atrioventricular block (Figure 2). He remained asymptomatic throughout all episodes; therefore, there was no indication for pacemaker insertion.

\section{Discussion}

Emery-Dreifuss muscular dystrophy is a rare inherited form of muscular dystrophy that can be inherited in an X-linked, autosomal dominant or, more rarely, an autosomal recessive pattern. Data suggest that the combined prevalence of the X-linked and autosomal dominant forms of Emery-Dreifuss muscular dystrophy is $0.1-0.4$ cases per 100000 , with the autosomal recessive subtype being extremely rare. ${ }^{1} \mathrm{X}$-linked Emery-Dreifuss muscular dystrophy is caused by a mutation in the EMD gene producing emerin and the FHL1 gene producing FHL1 protein, whereas the autosomal dominant and recessive forms are caused by a mutation in the LMNA gene producing lamin A/C proteins. ${ }^{2}$ Of note, although genetic testing was never done in this patient, his biopsy confirmed emerin-positive Emery-Dreifuss muscular dystrophy, which suggests his mutation affected one of the other protein products.

Emery-Dreifuss muscular dystrophy is characterized by early-onset contractures of elbows, Achilles tendons and cervical spine, with progressive muscle weakness and atrophy in a humeroperoneal distribution. Cardiac involvement is estimated to occur in more than $90 \%$ of patients with the condition, manifesting as a variety of conduction defects and variable dilated cardiomyopathy. ${ }^{3,4}$ More specifically, electrocardiography can show bradycardia from both sinoatrial or atrioventricular origins, as well as tachyarrhythmia from atrial or ventricular origins. ${ }^{5}$ In X-linked and autosomal dominant forms of EmeryDreifuss muscular dystrophy, there is a high rate of atrial fibrillation and flutter, and atrial standstill, which increases the risk of thromboembolic events and stroke. ${ }^{6}$ Patients with this condi-

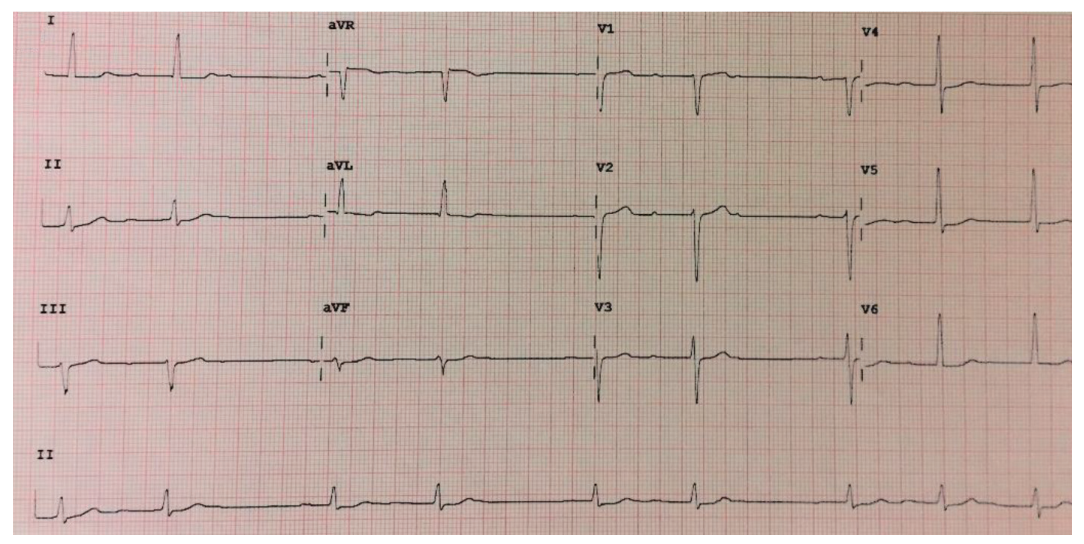

Figure 2: Twelve-lead electrocardiogram during hospital admission showing a 3:2 Mobitz type I second-degree atrioventricular block, with a heart rate of 57 beats/min. tion often present with substantial conduction disease by age 20 or 30 years, requiring pacing or implantable cardioverterdefibrillator placement to control symptoms and prevent sudden cardiac death. ${ }^{7}$

In 2017, the American Heart Association (AHA) published a scientific statement on the management of cardiac disease in patients with neuromuscular disease. ${ }^{8}$ The AHA statement provides background information on a variety of neuromuscular disorders in which there is cardiac involvement, including X-linked and recessive muscular dystrophies (Duchenne, Becker and Emery-Dreifuss), limb-girdle muscular dystrophy, myotonic dystrophy, congenital myopathy and myofibrillar myopathy. The statement highlights cardiac manifestations, including cardiomyopathy and arrhythmia, unique to each neuromuscular disease listed, which are summarized in Box 1. Recommendations focus on initial cardiac evaluation, follow-up, medical therapies and other therapies ranging from lifestyle modifications to cardioverter-defibrillator implantation.

\section{Cardiac screening and monitoring}

Patients with a neuromuscular disease should be screened with ECG and echocardiography at time of diagnosis even if they are asymptomatic. Patients with certain types of disease (i.e., myotonic dystrophy, mitochondrial myopathy [Barth syndrome, Friedreich ataxia], myofibrillar myopathy) should also have ambulatory ECG monitoring at diagnosis because of the higher risk of arrhythmia and sudden cardiac death. ${ }^{8}$

The AHA statement provides specific recommendations regarding follow-up, which are summarized in Box 1 . In general, patients should be followed regularly every 1 to 2 years with either ECG, echocardiogram or ambulatory ECG monitoring, depending on the particular type of neuromuscular disease. For example, patients with Limb-girdle muscular dystrophy type $1 \mathrm{~B}$ are at increased risk of sudden cardiac death and should have additional ambulatory ECG monitoring at least every 2 years if they are asymptomatic or every year if they have cardiac findings such as a cardiomyopathy or arrhythmia. Patients with myotonic dystrophy (DM1) are also at increased risk of sudden cardiac death and should undergo serial exercise stress testing, as physical exercise can be proarrhythmogenic. These patients also require further attention and investigations once they become symptomatic or meet certain ECG criteria. ${ }^{8}$

The AHA statement recommends, at minimum, annual evaluations with ECG and ambulatory ECG monitoring in patients with autosomal recessive Emery-Dreifuss muscular dystrophy, with an additional annual echocardiography test in patients with autosomal dominant or X-linked subtypes of the condition. ${ }^{8}$

Ambulatory monitoring can potentially help detect arrhythmia at an earlier stage because sudden cardiac death can often be the first presenting cardiac feature. ${ }^{6}$ Follow-up visits should be decided on an individual patient basis according to symptoms and rate of disease progression. ${ }^{8}$ 


\section{Management of cardiac involvement}

An ACE inhibitor or angiotensin receptor blocker, $\beta$-adrenergic blockade and mineralocorticoid antagonist are recommended in the setting of reduced ejection fraction. In some forms of muscular dystrophy, including Duchenne and Becker, some of these therapies are recommended even if patients still have preserved left ventricular function. ${ }^{8}$

Box 1: Neuromuscular diseases* and their corresponding clinical presentation, cardiac manifestations (cardiomyopathy and arrhythmia), risk of sudden cardiac death and recommended follow-up ${ }^{8}$

\begin{tabular}{|c|c|c|c|c|c|c|}
\hline \multicolumn{2}{|c|}{ Neuromuscular disease } & $\begin{array}{c}\text { Clinical } \\
\text { presentation }\end{array}$ & Cardiomyopathy & Arrhythmia & $\begin{array}{l}\text { Sudden } \\
\text { death }\end{array}$ & Follow-up \\
\hline \multirow[t]{3}{*}{$\begin{array}{l}\text { Muscular } \\
\text { dystrophy }\end{array}$} & Duchenne & $\begin{array}{l}\text { Proximal muscle } \\
\text { weakness } \\
\text { progressing to } \\
\text { respiratory failure }\end{array}$ & \multirow[t]{2}{*}{ Dilated (common) } & \multirow[t]{2}{*}{ VT } & \multirow[t]{2}{*}{-} & \multirow{2}{*}{$\begin{array}{l}\text { - ECG and echocardiography every } \\
2 \mathrm{yr} \text { in patients aged }<10 \mathrm{yr} \text { and } \\
\text { every } 1 \mathrm{yr} \text { in patients aged }>10 \mathrm{yr} \text { or } \\
\text { if there are cardiac findings in } \\
\text { asymptomatic patients } \\
\text { - Ambulatory ECG every } 1-3 \mathrm{yr}\end{array}$} \\
\hline & Becker & $\begin{array}{l}\text { Similar to Duchenne, } \\
\text { but later onset and } \\
\text { less severe course }\end{array}$ & & & & \\
\hline & $\begin{array}{l}\text { Emery- } \\
\text { Dreifuss }\end{array}$ & $\begin{array}{l}\text { Contractures (Achilles } \\
\text { tendons, elbows and } \\
\text { cervical spine) plus } \\
\text { humeroperoneal } \\
\text { weakness and } \\
\text { atrophy }\end{array}$ & Dilated (rare) & $\begin{array}{l}\text { AV block, atrial } \\
\text { flutter, AFib, VT }\end{array}$ & + & $\begin{array}{l}\text { - ECG, echocardiography and } \\
\text { ambulatory ECG every } 1 \mathrm{yr} \text { in } \\
\text { autosomal dominant and X-linked } \\
\text { recessive EDMD } \\
\text { - ECG and ambulatory ECG every } 1 \mathrm{yr} \\
\text { in autosomal recessive EDMD }\end{array}$ \\
\hline $\begin{array}{l}\text { Limb-girdle } \\
\text { muscular } \\
\text { dystrophy }\end{array}$ & $\begin{array}{l}\text { LGMD1B-E } \\
\text { and LGMD2B-I }\end{array}$ & $\begin{array}{l}\text { Proximal muscle } \\
\text { weakness of pelvic } \\
\text { and shoulder girdles }\end{array}$ & Dilated & AV block, AT, VT & $+($ LGMD1B $)$ & $\begin{array}{l}\text { - ECG and echocardiography every } \\
2 \text { yr in asymptomatic patients (for } \\
\text { all types of limb-girdle muscular } \\
\text { dystrophy except LGMD1B) or every } \\
1 \text { yr if cardiac findings are present } \\
\text { - ECG and ambulatory ECG every } 2 \mathrm{yr} \\
\text { in asymptomatic LGMD1B or every } \\
1 \text { yr if cardiac findings are present } \\
\text { - Symptoms should prompt } \\
\text { additional investigations }\end{array}$ \\
\hline \multirow[t]{2}{*}{$\begin{array}{l}\text { Myotonic } \\
\text { dystrophy }\end{array}$} & DM1 & $\begin{array}{l}\text { Muscle weakness } \\
\text { (facial, neck and } \\
\text { distal limb) and } \\
\text { myotonia }\end{array}$ & $\begin{array}{l}\text { Dilated, } \\
\text { hypertrophic }\end{array}$ & $\begin{array}{l}\text { AFib, atrial } \\
\text { flutter, VT }\end{array}$ & + & \multirow{2}{*}{$\begin{array}{l}\text { - ECG and ambulatory ECG every } 1 \mathrm{yr} \\
\text { plus echocardiography every } 2-4 \mathrm{yr} \\
\text { in asymptomatic patients } \\
\text { - Patients with palpitations, } \\
\text { dizziness, syncope, PR interval } \\
>240 \mathrm{~ms} \text {, QRS duration }>120 \mathrm{~ms} \text { or } \\
\text { AV block should be considered for } \\
\text { an EP study } \\
\text { - Serial exercise stress testing in } \\
\text { young patients with DM1 }\end{array}$} \\
\hline & DM2 & $\begin{array}{l}\text { Muscle weakness } \\
\text { (facial, neck and } \\
\text { distal limb) and } \\
\text { myotonia }\end{array}$ & Rare & Rare & - & \\
\hline \multirow[t]{2}{*}{$\begin{array}{l}\text { Mitochondrial } \\
\text { myopathy }\end{array}$} & Barth & $\begin{array}{l}\text { Neutropenia, } \\
\text { proximal skeletal } \\
\text { muscle weakness } \\
\text { and growth } \\
\text { restriction since birth }\end{array}$ & $\begin{array}{l}\text { Dilated, } \\
\text { hypertrophic }\end{array}$ & VT & + & $\begin{array}{l}\text { - ECG and echocardiography every } \\
6 \text { mo plus ambulatory ECG every } \\
1 \text { yr in asymptomatic infants } \\
\text { - ECG, echocardiography and } \\
\text { ambulatory ECG every } 1 \text { yr in } \\
\text { asymptomatic boys }\end{array}$ \\
\hline & $\begin{array}{l}\text { Friedreich } \\
\text { ataxia }\end{array}$ & $\begin{array}{l}\text { Ataxia, spasticity, } \\
\text { scoliosis, sensory } \\
\text { dysfunction and } \\
\text { diabetes }\end{array}$ & Hypertrophic & $\begin{array}{l}\text { AFib, atrial } \\
\text { flutter, AT }\end{array}$ & - & $\begin{array}{l}\text { - ECG and echocardiography every } \\
1 \text { yr in asymptomatic patients } \\
\text { - Ambulatory ECG every 1-4 yr in } \\
\text { asymptomatic patients } \\
\text { - Symptoms should prompt } \\
\text { ambulatory ECG monitoring }\end{array}$ \\
\hline \multicolumn{2}{|c|}{ Myofibrillar myopathy } & $\begin{array}{l}\text { Slowly progressive } \\
\text { muscle weakness } \\
\text { involving distal and } \\
\text { proximal muscles }\end{array}$ & $\begin{array}{l}\text { Dilated, } \\
\text { hypertrophic }\end{array}$ & $\begin{array}{l}\text { AV block, AT, } \\
\text { AFib, VT }\end{array}$ & - & $\begin{array}{l}\text { - ECG and echocardiography every } \\
1 \text { yr in asymptomatic patients } \\
\text { - Ambulatory ECG in symptomatic } \\
\text { patients }\end{array}$ \\
\hline
\end{tabular}

Note: $+=$ at risk for sudden cardiac death, $-=$ not at risk for sudden cardiac death, AFib = atrial fibrillation, AT = atrial tachycardia, $\mathrm{AV}=$ atrioventricular, DM1 = myotonic dystrophy 1 , $\mathrm{DM} 2$ = myotonic dystrophy 2, ECG = electrocardiography, EDMD = Emery-Dreifuss muscular dystrophy, EP = electrophysiology, LGMD1B-E = limb-girdle muscular dystrophy types 1B-E, LGMD2B-I = limb-girdle muscular dystrophy types 2B-I, VT = ventricular tachycardia. *This list includes specific diseases associated with increased risk of sudden cardiac death. 
Because of the high risk of sudden cardiac death in patients with neuromuscular disease, the AHA statement includes specific recommendations relating to the placement of implantable cardioverter-defibrillators. Placement of an implantable cardioverter-defibrillator is recommended in patients with left ventricular systolic dysfunction and an ejection fraction of $35 \%$ or less. In the absence of this criteria, placement should be considered in patients with a neuromuscular disease in which arrhythmia may be a predominant feature. This includes Duchenne, Becker and Emery-Dreifuss muscular dystrophies; myotonic dystrophy type 1; Friedreich ataxia; and limb-girdle muscular dystrophy type 1B. In Emery-Dreifuss muscular dystrophy, implantation should be considered in patients who do not meet the usual criteria if they have additional high-risk features, such as nonsustained ventricular tachycardia, an ejection fraction of less than $45 \%$, male sex and lamin A/C mutation. ${ }^{8}$

Cardiac involvement in patients with neuromuscular disorders can result in end-stage heart failure. The use of ventricular assist devices and cardiac transplantation has not been well studied, since these patients often have associated musculoskeletal weakness or restrictive lung disease, making them poor surgical candidates. There have been some case reports on successful cardiac transplantation in patients whose cardiomyopathy has progressed more rapidly than their skeletal muscle weakness, suggesting that this may be a potential option for select patients with neuromuscular disease. ${ }^{9,10}$

\section{Conclusion}

Despite known dilated cardiomyopathy for several years, the patient in this case remained largely asymptomatic until episodes of sustained ventricular tachycardia, a presentation that can be life-threatening. This case stresses the importance of early evaluation by a cardiologist and regular annual follow-up despite the absence of symptoms in patients with neuromuscular disease. Medical therapies including ACE inhibitor, $\beta$-blocker and mineralocorticoid antagonist should be initiated to optimize cardiac function. Early detection of arrhythmia and insertion of a pacemaker or defibrillator can be life-saving, as sudden cardiac death can often be the first presenting cardiac feature in this patient population.

\section{References}

1. Theodorn A, Rodrigues M, Roxburgh R, et al. Prevalence of muscular dystrophies: a systemic literature review. Neuroepidemiology 2014;43:259-68.

2. Puckelwartz M, McNally E. Emery-Dreifuss muscular dystrophy. Handb Clin Neurol 2011;101:155-66.

3. Boriani G, Gallina M, Merlini L, et al. Clinical relevance of atrial fibrillation/flutter, stroke, pacemaker implant, and heart failure in Emery-Dreifuss muscular dystrophy: a long-term longitudinal study. Stroke 2003;34:901-8.

4. Draminska A, Kuch-Wocial A, Szulc M, et al. Echocardiographic assessment of left ventricular morphology and function in patients with Emery-Dreifuss muscular dystrophy. Int J Cardiol 2005;102:207-10.

5. Bouhouch R, Elhouari T, Oukerraj L, et al. Management of cardiac involvement in neuromuscular diseases. Open Cardiovasc Med J 2008;2:93-6.

6. Rajdev A, Groh W. Arrhythmias in the muscular dystrophies. Card Electrophysiol Clin 2015;7:303-8.

7. Anselme F, Moubarak G, Savoure A, et al. Implantable cardioverter-defibrillators in lamin $\mathrm{A} / \mathrm{C}$ mutation carriers with cardiac conduction disorders. Heart Rhythm 2013;10:1492-8.

8. Feingold B, Mahle W, Auerbach S, et al. Management of cardiac involvement associated with neuromuscular diseases: a scientific statement from the American Heart Association. Circulation 2017;136:e200-31.

9. Wu RS, Gupta S, Brown R, et al. Clinical outcomes after cardiac transplantation in muscular dystrophy patients. J Heart Lung Transplant 2010;29:432-38.

10. Finsterer J, Bittner R, Grimm M. Cardiac involvement in Becker's muscular dystrophy, necessitating heart transplantation, 6 years before apparent skeletal muscle involvement. Neuromuscul Disord 1999;9:598-600.

\section{Competing interests: None declared.}

This article has been peer reviewed.

The authors have obtained patient consent.

Affiliations: Department of Medicine (Faiella), Queen Elizabeth II Health Sciences Centre, Dalhousie University, Halifax, NS; Division of Cardiology (Bessoudo), New Brunswick Heart Centre, Saint John Regional Hospital, Saint John, NB
Contributors: Both authors were involved in the conception and design of the manuscript. Whitney Faiella drafted the manuscript, which both authors revised. Both authors gave final approval of the version to be published and agreed to be accountable for all aspects of the work.

Correspondence to: Whitney Faiella, wh818396@dal.ca 